\title{
CORRELAÇÕES ENTRE ALTERAÇÕES DE FALA, RESPIRAÇÃO ORAL, DENTIÇÃO E OCLUSÃO
}

\section{Correlations between speech disorders, mouth breathing, dentition and occlusion}

\author{
Roberta Lopes de Castro Martinelli (1), Érica Fabiana Fornaro ${ }^{(2)}$, \\ Charlene Janaina Milanello de Oliveira ${ }^{(3)}$, Liege Maria Di Bisceglie Ferreira ${ }^{(4)}$, \\ Maria Inês Beltrati Cornacchioni Rehder ${ }^{(5)}$
}

\begin{abstract}
RESUMO
Objetivo: verificar as correlações entre alterações de fala e sinais de respiração oral ao tipo de dentição e oclusão, utilizando-se registros em vídeo. Métodos: estudo retrospectivo, de 397 pacientes, por meio de levantamento do roteiro de filmagem ROF. Tipos de alterações de fala e de sinais de respiração oral foram avaliados por Fonoaudiólogos Especialistas em Motricidade Orofacial e comparados com os tipos oclusais propostos por Angle e com parâmetros da dentição, ambos avaliados por Ortodontista. Para a análise estatística foi utilizado o programa SPSS (Statistical Package for Social Sciences), em sua versão 13.0. Para a análise de correlação de Spearman, todos os dados da avaliação foram pareados e analisados. Foi adotado o nível de significância de $5 \%$. Resultados: Considerando alterações de fala e dados de dentição e oclusão, observou-se paralelismo entre distorção e mordida cruzada, imprecisão e desvio ósseo de linha média inferior, travamento e sobressaliência, travamento e sobremordida, ceceio anterior e Classe III de Angle, ceceio anterior e mordida aberta, ceceio anterior e mordida cruzada; e ceceio anterior e desvio de linha média inferior. Observou-se ainda correlação de oposição entre travamento e mordida aberta, travamento e desvio ósseo de linha média inferior, ceceio anterior e Classe II-1 de Angle, ceceio anterior e sobressaliência; e ceceio anterior e sobremordida. Considerando os sinais de respiração oral e dados de dentição e oclusão, observou-se sinal de paralelismo entre eversão de lábio inferior e sobressaliência, acúmulo de saliva nas comissuras labiais e mordida cruzada, acúmulo de saliva nas comissuras labiais e falta de espaço intra-oral; e lábios entreabertos no repouso e Classe II-1 de Angle. Olheira e classe II-1 de Angle, eversão de lábio inferior e Classe II-1 de Angle; e lábio superior encurtado e sobremordida apresentaram correlação de oposição. Conclusões: o ceceio anterior está correlacionado a alterações de dentição e à Classe III de Angle; olheira, eversão do lábio inferior e lábios entreabertos no repouso são adaptações presentes na Classe II-1, não caracterizando respiração oral neste grupo; o acúmulo de saliva nas comissuras labiais foi o sinal de respiração oral que se correlacionou às alterações de dentição.
\end{abstract}

Descritores: Fonoaudiologia; Ortodontia; Transtornos da Articulação; Oclusão Dentária; Sistema Estomatognático; Respiração Bucal

(1) Fonoaudióloga da Clínica Magna Vox, Brotas, SP, Brasil; Especialização em Motricidade Orofacial.

(2) Fonoaudióloga da Associação dos Fornecedores de Cana de Piracicaba em Araras, SP; Especialização em Motricidade Orofacial.

(3) Fonoaudióloga da Associação de Pais e Amigos dos Excepcionais, APAE, Leme, SP, Brasil; Especialização em Motricidade Orofacial.
(4) Cirurgiã Dentista; Ortodontista da Clínica DB Ortodontia e Ortopedia Funcional dos Maxilares, Rio Claro, SP, Brasil; Mestre em Patofisiologia dos Órgãos e Sistemas pela Universidade Estadual de Campinas.

(5) Fonoaudióloga da Parole Fonoaudiologia, Rio Claro, SP, Brasil; Doutora em Distúrbios da Comunicação Humana pela Universidade Federal de São Paulo.

Conflito de interesses: inexistente 


\section{INTRODUÇÃO}

Para uma adequada produção da fala, é importante que o sistema estomatognático esteja anatômica e funcionalmente equilibrado, propiciando aos órgãos fonoarticulatórios condições para a realização dos movimentos necessários para sua produção'. Aspectos relacionados ao desenvolvimento ósseo e à situação oclusal devem ser considerados, uma vez que podem influenciar na produção da fala compondo o binômio formafunção, no qual a forma corresponde à parte óssea e a função ao termo genérico que relaciona cada parte do complexo orofacial, transformando-o num sistema dinâmico por meio de atividades coordenadas ${ }^{2,3}$. São muitos os fatores que interferem na produção dos sons da fala, sendo os problemas de dentição e oclusão, as alterações orofaciais e a respiração oral, alguns dos mais apontados como possíveis causas de risco de interferência ${ }^{4-10}$.

Além de a respiração oral ser apontada como um fator de risco para alterações na produção da fala, estudos a relacionam também com outras alterações no sistema estomatognático como, por exemplo, nas estruturas orais ${ }^{7,11}$. Alguns autores referem ser a respiração nasal fundamental para o crescimento e desenvolvimento adequados do complexo craniofacial, ao promover o funcionamento correto das demais funções estomatognáticas e que qualquer alteração no complexo orofacial perturba o equilíbrio do sistema orgânico ${ }^{3,7,11,12}$.

Considerando as implicações acima descritas, a avaliação clínica criteriosa em Motricidade Orofacial possibilita não só a compreensão das condições anatômicas e funcionais do sistema estomatognático como também o raciocínio clínico ${ }^{13}$. Dentro deste conceito, a filmagem em vídeo é uma forma de coleta de dados precisa e objetiva, uma vez que possibilita ao profissional registrar informações gerais e mínimas que o tempo e a memória não são capazes de armazenar. O registro da avaliação em vídeo facilita a qualificação, a comparação de dados e a verificação de detalhes através do congelamento das imagens, além disso, é possível recorrer à repetição dos dados coletados quantas vezes forem necessárias. Este procedimento tem se mostrado uma ferramenta útil no sentido de suprir algumas inquietações e responder às perguntas realizadas por pacientes, pais e outros profissionais. Estas questões normalmente se referem à necessidade ou não da terapia, prognóstico e evolução do caso $^{14}$.

Através dos registros em áudio e vídeos, complementares à avaliação clínica em Motricidade Orofacial, é possível verificar fatores funcionais e estruturais desencadeantes, mantenedores e compensatórios, bem como correlacionar forma e função. Estudar estas correlações é fundamental para fonoaudiólogos e ortodontistas uma vez que estabelece fatores favoráveis ou desfavoráveis para o tratamento a ser realizado ${ }^{15}$.

Sendo assim, o objetivo desta pesquisa é verificar as correlações entre alterações de fala e sinais de respiração oral ao tipo de dentição e oclusão, utilizando-se registros em vídeo.

\section{MÉTODOS}

A presente pesquisa foi realizada por meio do levantamento de dados do roteiro de filmagem Reabilitação, Ortodontia e Fonoaudiologia (ROF) ${ }^{16}$. Ao todo foram compilados dados das filmagens prétratamento de 397 pacientes, sendo 237 do sexo feminino $(59,7 \%)$ e 160 do sexo masculino $(40,3 \%)$, com idade entre 3 e 70 anos, com idade média de 20 anos e 4 meses, realizadas no período entre 1999 e 2006.

Estabelecemos como critérios de inclusão, serem pacientes da Clínica DB Ortodontia e Ortopedia Funcional dos Maxilares cujo registro em vídeo tenha sido realizado no primeiro dia de entrada na clínica. Foram excluídos pacientes portadores de doenças neurológicas, anomalias craniofaciais, disfunção temporomandibular e/ou que tivessem realizado ou realizando fonoterapia na área de motricidade orofacial. Foram excluídos ainda aqueles cuja qualidade de filmagem comprometia áudio ou visualmente uma avaliação fidedigna.

Os registros da filmagem foram feitos em fita VHS individual para cada sujeito com a câmara GR-AMX300 da JVC colocada sobre tripé. Todos os sujeitos foram filmados no mesmo local e pela Ortodontista responsável pela Clínica DB de Ortodontia, seguindo as etapas do roteiro $\mathrm{ROF}^{16}$. O roteiro ROF contém 5 etapas de coleta de dados através de filmagem: seqüência de fala, dinâmica mandibular, dentição/oclusão, mastigação/deglutição e postura. Considerando os objetivos deste estudo utilizamos as seguintes etapas:

1. Sequência de fala: Paciente em pé. Registro frontal da face em repouso (figura 1) e solicitações: falar nome e idade, contar os números de 1 a 20 e cantar "parabéns a você".

2. Dentição/oclusão: Paciente sentado em cadeira odontológica. Registro frontal, lateral direita e lateral esquerda com os dentes em oclusão cêntrica, utilizando um abridor de boca odontológico (figuras 2,3 e 4). Registro da altura do palato com a boca aberta sem abridor de boca odontológico (figura 5). Solicitações: realizar movimentos laterais de mandíbula mantendo 
Figuras 1 a 5 - exemplos de imagens, adquiridas através da tecla pause a fim de permitir a avaliação Fonoaudiológica e Ortodôntica, retiradas do roteiro de filmagem ROF $^{16}$

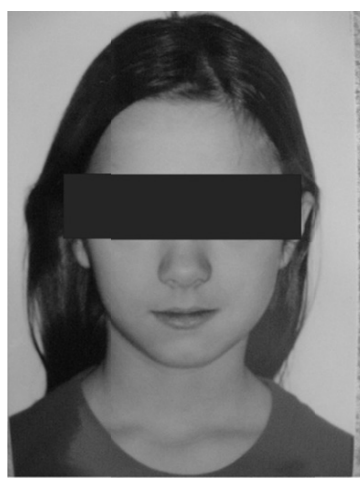

Figura 1 - registro frontal em repouso
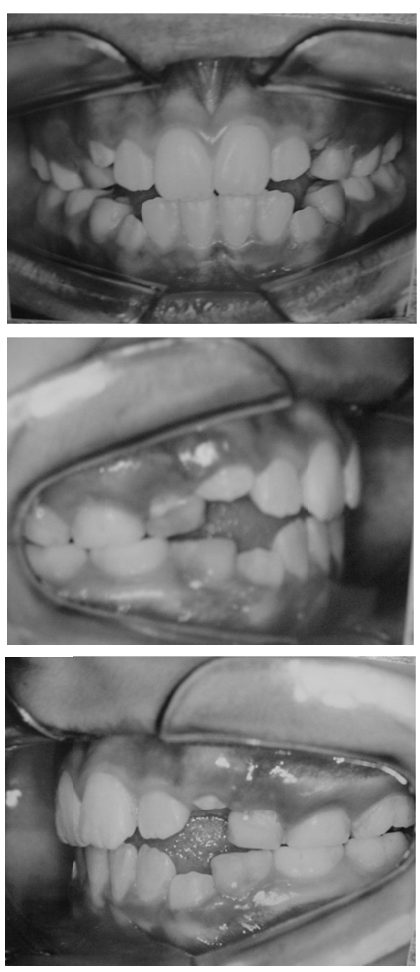

Figuras 2, 3 e 4 - registros da oclusão e da dentição

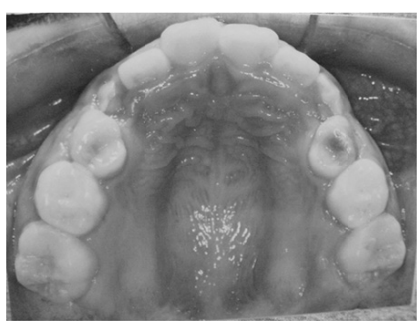

Figura 5 - registro da configuração do palato os dentes em oclusão, deslizar a mandíbula no sentido póstero-anterior com dentes em oclusão.

A partir das informações registradas nos filmes nas duas etapas descritas acima, os dados relacionados à fala e aos sinais de respiração oral foram analisados/avaliados através da etapa 1 do roteiro ROF, por meio de observação visual e julgamento auditivo, por três Fonoaudiólogos especialistas em motricidade orofacial. A avaliação da dentição e da oclusão foi realizada pelo Ortodontista responsável pela Clínica DB de Ortodontia, a partir da observação visual da etapa 2 do roteiro ROF, utilizando velocidade normal, slow motion e congelamento de imagem. Em casos de visualização insuficiente, a documentação Ortodôntica foi utilizada para a confirmação desta avaliação.

Os Fonoaudiólogos avaliadores submeteram-se previamente a um treinamento visual e auditivo de um banco de dados coletados nos mesmos moldes desta pesquisa (projeto piloto) a fim de uniformizar os resultados das avaliações de produção de fala e sinais de respiração oral, bem como verificar se todos os itens a serem avaliados eram passíveis de verificação através do instrumento proposto. As filmagens realizadas com close no rosto e a qualidade do áudio permitiram a avaliação visual e perceptivo-auditiva de todos os aspectos propostos.

A avaliação Fonoaudiológica foi realizada através da projeção das filmagens ampliadas, com sistema de amplificação sonora, estando presentes os três avaliadores. As imagens foram projetadas o número de vezes que os avaliadores acharam necessário. As avaliações foram realizadas individualmente em uma ficha de registro, através de marcação positiva ou negativa (figura 6). Ao término de cada avaliação, os resultados foram apresentados oralmente, no caso de discordância de um dos avaliadores sobre qualquer aspecto avaliado, as imagens foram retomadas, discutidas e reavaliadas. Foi considerado como resultado final o consenso de $100 \%$ dos avaliadores em todos os aspectos propostos.

$\mathrm{Na}$ avaliação da fala foram considerados os seguintes aspectos: presença de distorção, omissão, substituição, adição, imprecisão, travamento, ceceio anterior e lateral. As ocorrências de omissão e substituição foram avaliadas a partir do que é considerado normal para a idade, segundo a literatura consultada ${ }^{17,18}$.

Considerou-se distorção, os ajustes ou compensações utilizadas para a produção de um fonema ou um grupo de fonemas; omissão quando um fonema ou mais fonemas não foram produzidos; substituição quando ocorreu a troca de fonemas por 


\begin{tabular}{|l|l|}
\hline PACIENTE & \\
\hline IDADE & \\
\hline AVALIAÇÃo DE FALA & \\
\hline Distorção & \\
\hline Omissão & \\
\hline Substituição & \\
\hline Adição & \\
\hline Imprecisão & \\
\hline Ceceio anterior & \\
\hline Ceceio lateral & \\
\hline Travamento & \\
\hline SINAIS DE RESPIRAÇÃO ORAL & \\
\hline Olheira & \\
\hline Eversão do lábio inferior & \\
\hline Acúmulo de saliva nas comissuras labiais & \\
\hline Lábios entreabertos no repouso & \\
\hline Lábios ressecados & \\
\hline Lábio superior encurtado & \\
\hline DENTIÇÃo OCLUSÃo & \\
\hline Classificação da oclusão & \\
\hline CLI & \\
\hline CLII - div 1 & \\
\hline CLII - div 2 & \\
\hline CLIII & \\
\hline Classificação da dentição & \\
\hline Sobressaliência & \\
\hline Sobremordida & \\
\hline Mordida aberta & \\
\hline Biprotusão & \\
\hline Cruzamento & \\
\hline Falta de espaço intra oral & \\
\hline Desvio ósseo de linha média inferior & \\
\hline
\end{tabular}

Figura 6 - Parâmetros do roteiro ROF $^{16}$ utilizados. As ocorrências foram marcadas com xis

outros fonemas; adição, quando houve acréscimo de sons na fala; imprecisão, quando a fala apareceu imprecisa como um todo e não em sons específicos e como travamento quando houve diminuição da abertura de boca para a produção da fala ${ }^{4}$.

Conceituou-se como ceceio a produção incorreta dos sons fricativos linguo-alveolares /s/ e /z/, considerando que a produção correta é realizada com constrição do fluxo aéreo entre a parte anterior da língua e o alvéolo inferior e o conseqüente direcionamento do fluxo para os incisivos inferiores. Considerou-se como ceceio anterior quando o fluxo respiratório foi emitido centralmente, mas a língua encontrava-se mal posicionada nos planos vertical e ântero-posterior, produzindo os sons entre os dentes anteriores; como ceceio lateral quando o fluxo respiratório foi dividido lateralmente havendo escape lateral de ar pela cavidade oral durante a produção dos fricativos linguo-dentais ${ }^{19}$.

Embora o ceceio faça parte do grupo de distorções, neste estudo foi avaliado separadamente a fim de verificarmos possíveis correlações específicas com a oclusão e a dentição, ou seja, as ocorrências de ceceio anterior e lateral foram computadas separadamente não estando inseridas no grupo de distorções.

$\mathrm{Na}$ avaliação da respiração foram observados os seguintes sinais ${ }^{20}$ : olheira, eversão do lábio inferior, acúmulo de saliva nas comissuras labiais, lábios entreabertos no repouso, lábios ressecados, lábio superior encurtado. Os sinais foram avaliados individualmente através de marcação com xis na folha de registro, para os itens alterados (figura 6).

A análise Ortodôntica da oclusão e da dentição foi realizada a partir da etapa 2 do roteiro ROF. Coube ao Ortodontista classificar a oclusão como classe I, classe II -1 , classe II -2 , classe III de acordo com Angle ${ }^{21}$; na avaliação da dentição foi considerada a ocorrência ou não de: sobressaliência, sobremordida, mordida aberta, biprotrusão, cruzamento, falta de espaço intra-oral e desvio ósseo de linha média inferior. A falta de espaço intra-oral foi considerada a partir da ocorrência de apinhamento dentário, atresia do palato e dificuldade no deslizamento lateral e anterior da mandíbula. O desvio da linha média óssea inferior através da imagem frontal.

A presente pesquisa foi avaliada pelo Comitê de Ética e Pesquisa (CEP) do CEFAC - PósGraduação em Saúde e Educação, aprovada sob o número 187/05, considerada como sem risco e sem necessidade do Termo de Consentimento livre e Esclarecido.

Após a coleta, os dados foram compilados de forma numérica e percentual e descritos em tabelas. Para a análise estatística dos dados compilados, foi adotado o nível de significância de $5 \%(0,0050)$, para aplicação dos testes estatísticos. Foi utilizado o programa SPSS (Statistical Package for Social Sciences), em sua versão 13.0, para a obtenção dos resultados que foram descritos em tabelas. Optou-se pela análise de correlação de Spearman, por meio da qual todos os dados da avaliação de fala, respiração, dentição e oclusão foram pareados e analisados. A análise de correlação de Spearman é uma medida de comportamento entre dados pareados, que avalia o nível de significância estatística e o tipo de correlação. Considerou-se o nível de correlação com significância menor que 5\%. Os dados estatisticamente significantes foram marcados com asterístico. 
A análise de correlação de Spearman ainda denota o sinal da correlação: sinal positivo para paralelismo e sinal negativo para oposição. 0 paralelismo demonstra uma relação proporcional, paralela e direta, entre os dados pareados: quanto maior o valor de um dado, maior o valor do dado correspondente pareado, e vice-versa. A oposição demonstra uma relação proporcional de oposição entre os dados pareados: quanto maior o valor de um dado, menor o valor do dado correspondente pareado, e vice e versa ${ }^{22}$.

\section{RESULTADOS}

Os resultados da análise da fala, sinais de respiração oral, dentição e oclusão de 397 pacientes por meio de um roteiro específico de filmagem foram organizados em duas tabelas descritivas e duas de correlação.

Considerando a análise de fala, observou-se que o travamento foi à alteração mais freqüente, acometendo 103 sujeitos (25,94\%) da amostra; seguido por $75(18,89 \%)$ com ceceio anterior, 23 (5,79\%) com imprecisão, 2 (0,5\%) com distorção, 2 $(0,5 \%)$ com omissão $(0,5 \%)$ e $2(0,5 \%)$ com substituição. Não observamos a ocorrência de ceceio lateral e adição de fonemas na fala nos sujeitos estudados. Com relação aos sinais de respiração oral, 196 sujeitos $(49,37 \%)$ apresentaram olheira, 131 (33\%) eversão de lábio inferior, 117 (29,47\%) lábios entreabertos no repouso, 98 (24,59\%) lábios ressecados, 21 (5,29\%) lábios superiores encurtados e em 15 (3,78\%) sujeitos observou-se acúmulo de saliva nas comissuras labiais (tabela 1).

Tabela 1 - Distribuição numérica e percentual da avaliação da produção da fala e sinais de respiração oral, seguindo o roteiro ROF $(n=397)$

\begin{tabular}{lcc}
\hline Avaliação & $\mathbf{N}$ & $\%$ \\
\hline Produção da fala & & \\
Distorção & 2 & 0,50 \\
Omissão & 2 & 0,50 \\
Substituição & 2 & 0,50 \\
Adição & 0 & 0 \\
Imprecisão & 23 & 5,79 \\
Travamento & 103 & 25,94 \\
Ceceio & & \\
$\quad$ Anterior & 75 & 18,89 \\
$\quad$ Lateral & 0 & 0 \\
\hline Sinais de respiração oral & & \\
Olheira & 196 & 49,37 \\
Eversão do lábio inferior & 131 & 33,00 \\
Acúmulo de saliva nas comissuras labiais & 15 & 3,78 \\
Lábios entreabertos no repouso & 117 & 29,47 \\
Lábios ressecados & 98 & 24,69 \\
Lábio superior encurtado & 21 & 5,29 \\
\hline
\end{tabular}

Seguindo a classificação de Angle, 207 sujeitos $(52,14 \%)$ apresentaram Classe I, $159(40,05 \%)$ Classe II divisão 1, 26 (6,55\%) Classe III e 5 (1,26\%) Classe II divisão 2. Considerando a dentição, 279 sujeitos $(70,26 \%)$ apresentaram desvio ósseo de linha média inferior, $222(55,92 \%)$ sobressaliência, $211(53,15 \%)$ sobremordida, $203(51,13 \%)$ falta de espaço intra-oral, 125 (31,49\%) cruzamento, $108(27,2 \%)$ e 21 (5,29\%) biprotrusão (Tabela 2). Tanto na avaliação da fala quanto nos sinais de respiração oral e na dentição observou-se que alguns aspectos ocorreram no mesmo sujeito de forma concomitante. O cálculo da porcentagem foi realizado considerando o número de ocorrências de determinada alteração no total de sujeitos estudados (397).

A análise de correlação de Spearman mostrou correlações de paralelismo e oposição, estatisticamente significantes, entre os achados de alterações de fala, sinais de respiração oral, dentição e oclusão. Considerando alterações de fala e dados de dentição e oclusão, observou-se paralelismo entre distorção e mordida cruzada, imprecisão e desvio ósseo de linha média inferior, travamento e sobressaliência, travamento e sobremordida, ceceio anterior e Classe III de Angle, ceceio 
Tabela 2 - Distribuição numérica e percentual de parâmetros de avaliação da oclusão e da dentição em pacientes filmados, seguindo o roteiro ROF $(n=397)$

\begin{tabular}{lcc}
\hline Parâmetros & N & $\%$ \\
\hline Oclusão & & \\
Classe I & 207 & 52,14 \\
Classe II-1 & 159 & 40,05 \\
Classe II-2 & 5 & 1,26 \\
Classe III & 26 & 6,55 \\
Total & 397 & 100 \\
\hline Dentição & & \\
Sobressaliência & 222 & 55,92 \\
Sobremordida & 211 & 53,15 \\
Mordida aberta & 108 & 27,20 \\
Biprotrusão & 21 & 5,29 \\
Cruzamento & 125 & 31,49 \\
Falta de espaço & 203 & 51,13 \\
Desvio ósseo de linha média inferior & 279 & 70,28 \\
\hline
\end{tabular}

anterior e mordida aberta, ceceio anterior e mordida cruzada; e ceceio anterior e desvio de linha média inferior. Observou-se ainda correlação de oposição entre travamento e mordida aberta, travamento e desvio ósseo de linha média inferior, ceceio anterior e Classe II-1 de Angle, ceceio anterior e sobressaliência; e ceceio anterior e sobremordida (Tabela 3). Considerando os sinais de respiração oral e dados de dentição e oclusão, observou-se sinal de paralelismo entre eversão de lábio inferior e sobressaliência, acúmulo de saliva nas comissuras labiais e mordida cruzada, acúmulo de saliva nas comissuras labiais e falta de espaço intra-oral; e lábios entreabertos no repouso e Classe II-1 de Angle. Olheira e classe II-1 de Angle, eversão de lábio inferior e Classe II-1 de Angle; e lábio superior encurtado e sobremordida apresentaram correlação de oposição (Tabela 4).

Tabela 3 - Análise de correlação por pares, das alterações de fala, dentição e oclusão, com significância menor que $5 \%$

\begin{tabular}{lcc}
\hline Par de variáveis & $\begin{array}{c}\text { Sinal da } \\
\text { correlação }\end{array}$ & $\begin{array}{c}\text { Valor da } \\
\text { significância (p) }\end{array}$ \\
\hline Produção da fala & & \\
Distorção x mordida cruzada & + & $0,004^{*}$ \\
Imprecisão x desvio de linha média inferior & + & $0,002^{*}$ \\
Travamento x sobressaliência & + & $0,003^{*}$ \\
Travamento x sobremordida & + & $0,004^{*}$ \\
Travamento x mordida aberta & - & $0,039^{*}$ \\
Travamento x desvio ósseo de linha média inferior & - & $0,001^{*}$ \\
\hline Ceceio & & \\
Anterior x classe II-1 & - & $0,063^{*}$ \\
Anterior x classe III & + & $0,000^{*}$ \\
Anterior x Sobressaliência & - & $0,018^{*}$ \\
Anterior x sobremordida & - & $0,000^{*}$ \\
Anterior x mordida aberta & + & $0,000^{*}$ \\
Anterior x mordida cruzada & + & $0,026^{*}$ \\
Anterior x desvio ósseo de linha média inferior & + & $0,000^{*}$ \\
\hline
\end{tabular}


Tabela 4 - Análise de correlação por pares, dos sinais de respiração oral, dentição e oclusão, com significância menor que $5 \%$

\begin{tabular}{lcc}
\hline Par de variáveis & $\begin{array}{c}\text { Sinal de } \\
\text { correlação }\end{array}$ & $\begin{array}{c}\text { Valor da } \\
\text { significância (p) }\end{array}$ \\
\hline Sinais de respiração oral & - & $0,023^{*}$ \\
$\quad$ Olheira x classe II-1 & - & $0,035^{*}$ \\
$\quad$ Eversão de lábio inferior x classe II-1 & + & $0,044^{*}$ \\
$\quad$ Eversão de lábio inferior x sobressaliência & + & $0,015^{*}$ \\
$\quad \begin{array}{l}\text { Acúmulo de saliva nas comissuras labiais x mordida } \\
\text { cruzada }\end{array}$ & + & $0,035^{*}$ \\
Acúmulo de saliva nas comissuras labias x falta de & & $0,006^{*}$ \\
espaço intra-oral & + & $0,019^{*}$ \\
$\quad$ Lábios entreabertos no repouso x classe II-1 & - & \\
\hline
\end{tabular}

Legenda

Sinal positivo: correlação de paralelismo

Sinal negativo: correlação de oposição

Asterisco *: estatisticamente significante

\section{DISCUSSÃO}

A consideração dos aspectos morfológicos e fisiológicos do sistema estomatognático, bem como da classificação do tipo de oclusão e dentição foram fundamentais para a discussão dos resultados deste estudo, que enfoca as correlações entre fala, respiração oral, dentição e oclusão. É importante considerar que as alterações na produção da fala podem variar, dependendo da gravidade do problema estrutural, porém esta variável não foi incluída neste estudo. A literatura consultada descreve que o sistema estomatognático é composto por ossos, dentes, articulação temporomandibular, músculos, sistema vascular e nervoso e espaços vazios. Qualquer alteração, principalmente sobre os dentes, poderá levar a um desequilíbrio de todo sistema, acarretando alterações de fala ${ }^{1,4,23-26}$. As alterações de oclusão podem advir de várias causas, sendo a respiração oral uma delas. Nos respiradores orais a língua tende a permanecer mais baixa na cavidade oral, podendo ocasionar mudanças nos tecidos musculares e alterar as funções do sistema estomatognático, incluindo a produção da fala ${ }^{11}$.

É importante considerar que a baixa ocorrência de omissão e substituição no grupo estudado pode estar relacionada ao número reduzido de crianças com idade inferior a cinco anos incluído no estudo e que a amostra escolhida para a avaliação da produção da fala possa ter sido restrita.

No cruzamento, observado na relação dentária, ocorre uma redução das dimensões transversais do arco superior, levando ao desvio da simetria facial e a alterações na função mandibular. A literatura estudada é concordante na ocorrência de mastigação unilateral nos casos de cruzamento $^{27}$, entretanto a função mastigatória não foi objeto deste estudo. Com relação à fala, verificou-se distorção fonêmica associada à mordida cruzada. Embora clinicamente não significante, uma vez que apenas dois sujeitos apresentaram distorção enquanto que cento e vinte e cinco apresentaram cruzamento, a relação de co-ocorrência paralela pode estar relacionada ao desequilíbrio funcional da musculatura da língua. Tal desequilíbrio pode interferir na produção dos sons fricativos, devido ao rebaixamento do tônus e ao aumento do volume lingual, por conseqüência do posicionamento freqüente na arcada inferior; e ao aumento da profundidade palatina, dificultando a produção dos fonemas línguo-palatais ${ }^{28}$. A imprecisão articulatória e o ceceio anterior co-relacionados ao desvio de linha média inferior também podem ocorrer pelo desequilíbrio ósseo-funcional horizontal uma vez que modificações estruturais da cavidade oral alteram significativamente os pontos articulatórios, podendo levar a distorções ou imprecisões na fala ${ }^{1,5,23}$

O desvio ósseo de linha média é mais um fator de desequilíbrio funcional, nestes casos geralmente há um desvio da mandíbula durante a produção dos sons da fala, podendo gerar imprecisão e ceceio. A correlação de oposição com travamento articulatório provavelmente se deve à dificuldade de desoclusão mandibular durante a produção dos sons da fala, característica do travamento.

Os incisivos superiores podem trespassar os incisivos inferiores tanto no sentido horizontal resultando na sobressaliência, quanto no sentido vertical resultando na sobremordida. A sobressaliência reduz o espaço intra-oral devido à redução do arco maxilar e atresia do palato, a sobremordida também reduz o espaço intra-oral devido à diminuição 
da dimensão vertical. Em ambas, a redução das dimensões intra-orais podem dificultar os movimentos necessários da língua para a produção da fala ${ }^{29}$. O travamento articulatório decorrente é compensatório e por vezes a única possibilidade de produção de fala inteligível ${ }^{4}$. O oposto ocorre na mordida aberta, na qual o distanciamento entre as bordas incisais superiores e inferiores dos dentes anteriores pode minimizar a ocorrência de travamento articulatório.

Os achados de co-ocorrência paralela entre ceceio e mordida aberta corroboram com a literatura estudada que cita a produção adaptativa dos fricativos /s/ e /z/ nos casos de mordida aberta devido à elevação, protrusão e interposição da língua 8,19,30. Tanto a mordida aberta anterior quanto a lateral resultam em espaços livres para a protusão lingual, porém a mordida aberta anterior permite maior percepção visual do movimento anterior da língua, justificando a correlação com o ceceio anterior.

Embora não tenha sido objetivo deste estudo, é importante citar que a mordida aberta anterior funcional tem os hábitos deletérios e a respiração oral como fatores desencadeantes, mantenedores e/ou agravantes devendo ser cuidadosamente avaliados e tratados por uma equipe multidisciplinar.

O posicionamento baixo e anterior da língua sobre os incisivos inferiores nos indivíduos Classe III de Angle está relacionado à protrusão da base óssea inferior em relação à superior justificando a correlação de paralelismo com o ceceio anterior ${ }^{10}$. Em contrapartida a correlação de oposição entre o ceceio anterior e indivíduos com Classe II-1, procede, uma vez que o estreitamento da arcada superior e a protrusão dos incisivos superiores tendem a não alterar o modo e o ponto articulatório dos fricativos /s/ e /z/.

A Síndrome do respirador oral é caracterizada por um conjunto de sinais e sintomas; os sinais incluem: olheira, eversão do lábio inferior, acúmulo de saliva nas comissuras labiais, lábios entreabertos no repouso, lábios ressecados, lábio superior encurtado $^{2,20}$. A respiração oral produz sérias alterações estéticas e funcionais no sistema estomatognático; as características do quadro clínico variam de acordo com o biotipo do paciente e o tempo de persistência do problema ${ }^{2,20}$. Neste estudo verificou-se correlação de oposição entre Classe II-1, olheira e eversão de lábio inferior, indicando que os indivíduos portadores de Classe II-1 não são necessariamente respiradores orais, quando considerado presença de olheira e eversão de lábio inferior, como sinais clínicos da respiração oral. Assim, a presença de olheira e eversão de lábio inferior não são sinais suficientes para caracterizar o padrão respiratório oral, uma vez que a eversão labial poderia ser considerada uma adaptação para a produção da fala. A correlação de paralelismo com lábios entreabertos no repouso confirma a hipótese anterior indicando que a sobressaliência decorrente da Classe II-1 favorece a interposição do lábio inferior entre os incisivos, como processo adaptativo ${ }^{4}$.

A correlação de oposição entre sobremordida e lábio superior encurtado se deve ao fato da redução da dimensão vertical da cavidade oral característica da sobremordida facilitar o vedamento labial ${ }^{29}$. A própria condição óssea nos casos de sobremordida poderia facilitar a função labial de vedamento.

De forma geral, os resultados deste estudo contribuem para um maior entendimento das relações entre produção de fala, sinais de respiração oral, oclusão e dentição, uma vez que foi possível a confirmação de algumas correlações ósseas e funcionais. Na presença de alterações co-existentes, profissionais de áreas afins, Fonoaudiólogos e Ortodontistas, podem ter seu trabalho limitado caso não haja integração e ação multidisciplinar.

Embora não tenha sido o objetivo desta pesquisa, os resultados obtidos apontam para a necessidade de um estudo mais aprofundado considerando as ocorrências relacionadas à faixa etária, resultados da avaliação clínica Fonoaudiológica e a inclusão de dados da documentação ortodôntica como tipologia facial e crescimento crânio-facial.

\section{CONCLUSÕES}

- Com base nos achados deste estudo pode-se concluir que:

- O ceceio anterior está correlacionado a alterações de dentição e à Classe III de Angle.

- Olheira, eversão do lábio inferior e lábios entreabertos no repouso são adaptações de forma presentes na Classe II-1, não caracterizando respiração oral neste grupo.

- O acúmulo de saliva nas comissuras labiais foi o sinal de respiração oral que se correlacionou às alterações de dentição. 


\section{ABSTRACT}

Purpose: to check the correlations among speech disorders and mouth breathing symptoms with the type of dentition and occlusion, using video recordings. Methods: a retrospective study with 397 patients, by studying the shooting script - ROF. Types of speech disorders and mouth breathing symptoms were assessed by Orofacial Motricity Specialist Speech and Language Pathologists and compared with the occlusal types proposed by Angle and with the dentition parameters, both evaluated by an Orthodontist. For the statistical analysis we used the program SPSS (Statistical Package for Social Sciences), version 13.0. For analyzing Spearman correlation, all assessment data were matched and analyzed. The adopted significance level was $5 \%$. Results: Considering speech disorders and dentition and occlusion data, we noted parallelism between distortion and crossbite, imprecision and bone deviation of lower midline line, locking and overjet, locking and overbite, frontal lisp and Angle Class III malocclusion, frontal lisp and malocclusion, frontal lisp and open bite, frontal lisp and crossbite; and frontal lisp and lower midline deviation. We also noted correlated opposition between locking and openbite, locking and bone deviation of lower bone midline, frontal lisp and Angle Class II-1 malocclusion, frontal lisp and overjet; and frontal lisp and overbite. Considering mouth breathing symptoms and dentition and occlusion data, we noted a symptom of parallelism between the protrusion of lower lip and overjet, accumulation of saliva on the labial commissures and crossbite, accumulation of saliva on the labial commissures and lack of intra-oral room; Half-opened lips at rest and Angle Class II-1 malocclusion. Dark eye circle and Angle Class II-1 malocclusion, protrusion of lower lip and Class II-1 malocclusion; and shortened upper lip and overbite show correlated opposition. Conclusions: the anterior lisp is correlated to dentition disorders and Angle Class III malocclusion; dark eye circle, protrusion of lower lip and half-opened lips in rest are adaptations found in Angle Class II-1 malocclusion, not characterizing oral breathing in this group; the accumulation of saliva on the labial commisures was a symptom of mouth breathing that was correlated with the disorders in dentition.

KEYWORDS: speech therapy; orthodontics; joint disorders; dental occlusion; stomatognathic system; mouth breathing

\section{REFERÊNCIAS}

1. Lemos CM, Wilhelmsen MSW, Mion OG, Mello Junior JF. Alterações funcionais do sistema estomatognático em pacientes com rinite alérgica: estudo caso-controle. Braz J Otorhinolaryngol. 2009;75(2):268-74.

2. Tessitore A. Alterações oromiofuncionais em Respiradores Orais. In: Ferreira LP, Befi-Lopes DM, Limongi SCO. Tratado de fonoaudiologia. São Paulo: Roca; 2004. p. 261-276.

3. Castillo-Morales R. Terapia de Regulação Orofacial. São Paulo: Memnon; 1999. 195p.

4. Marchesan IQ. Alterações de fala de origem músculo-esquelética. In: Ferreira LP, Befi-Lopes DM, Limongi SCO. Tratado de fonoaudiologia. São Paulo: Roca; 2004; p. 292-303.

5. Oliveira CF, Busanello AR, Silva AMT. Ocorrência de má oclusão e distúrbio articulatório em crianças respiradoras orais de escolas públicas de Santa Maria, Rio Grande do Sul. RGO. 2008; 56(2):169-74. 6. Maciel CTV, Barbosa MH, Toldo CA, Faza FCB, Chiappetta ALML. Disfunções orofaciais nos pacientes em tratamento ortodôntico. Rev. CEFAC. 2006; 8(4):456-66.

7. Suliano AA, Rodrigues MJ, Caldas Júnior AF, Fonte PP, Porto-Carreiro CF. Prevalência de maloclusão e sua associação com alterações funcionais do sistema estomatognático entre escolares. Cad. Saúde Pública. 2007; 23(8):1913-23.

8. Maciel CTVM, Leite ICG. Aspectos etiológicos da mordida aberta anterior e suas implicações nas funções orofaciais. Pró-Fono. 2005; 17(3):293-302.

9. Pena CR, Pereira MMB, Bianchini EMG. Características do tipo de alimentação e da fala de crianças com e sem apinhamento dentário. Rev. CEFAC. 2008; 10(1):58-67.

10. Pereira $A C$, Jorge TM, Ribeiro Júnior PD, Berretin-Felix G. Características das funções orais de indivíduos com má oclusão Classe III e diferentes tipos faciais. Dental Press Ortodon Ortop Facial. 2005; 10(6);111-9.

11. Andrade FV, Andrade DV, Araújo AS, Ribeiro ACC, Deccax LDG, Nemr K. Alterações estruturais de órgãos fonoarticulatórios e más oclusões 
dentárias em respiradores orais de 6 a 10 anos. Rev. CEFAC. 2005; 7(3):318-25.

12. Abreu RR, Rocha RL, Lamounier JA, Guerra AFM.Etiology, clinical manifestations and concurrent findings in mouth-breathing children. J Pediatr 2008; 84(6):529-35.

13. Genaro KF, Berretin-Felix, Rehder MIBC, Marchesan IQ. Avaliação Miofuncional Orofacial Protocolo MBGR. Rev. CEFAC. 2009; 11(2):237-55. 14. Tanigute CC. A documentação como ferramenta para o diagnóstico e controle de terapia. In: Marchesan IQ. Tratamento da deglutição: a atuação do fonoaudiólogo em diferentes países. São José dos Campos: Pulso; 2005. p.107-15.

15. Ramires RR, Ferreira LP, Marchesan IQ, Cattoni DM, Silva MAA. Tipologia facial aplicada à Fonoaudiologia: revisão de literatura. Rev Soc Bras Fonoaudiol. 2010;15(1):140-5.

16. Rehder MI, Ferreira LB, Silva JR. Proposta de avaliação em vídeo na clínica multidisciplinar: fonoaudiológica, ortodôntica e reabilitadora. Anais do VI Congresso Internacional de Fonoaudiologia. São Paulo; 1999.

17. Wertzner HF. Estudo da aquisição do sistema fonológico: o uso de processos fonológicos em crianças de três a sete anos. Pró-fono. 1995; $7(1): 21-6$.

18. Wetzner HF. Fonologia: Desenvolvimento e Alterações. In: Fernandes FDM, Mendes BCA, Navas ALPG. Tratado de Fonoaudiologia. São Paulo: Roca; 2009. p 281-90.

19. Leite AF, Silva SB, Britto ATBO, Di Ninno CQMS. Caracterização do ceceio em pacientes de um Centro Clínico de Fonoaudiologia. Rev Soc Bras Fonoaudiol. 2008; 13(1):30-6.

20. Marchesan IQ. Avaliando e tratando o sistema estomatognático. In: Lopes Filho OC. Tratado de fonoaudiologia. São Paulo: Roca; 1997; p. 763-80. 21. Angle EH. Maloclusion of teeth. White Dental Manufacturing. Philadelphia; 1907.
22. Rosner B. Fundamentals of biostatistics. Boston: Duxbury press; 1986.

23. Perlato NM, Nahas-Scocate ACR, Jabur LB, Ferreira RI, Garib DG, Valle-Corotte KM. Correlação entre a presença de ceceio anterior e os tipos de trespasse vertical interincisivos na dentadura decídua. Revista de Odontologia da Universidade de São Paulo. 2009; 21(2): 98-103.

24. Garcia-Flores G, Figueroa AR, Muller V, Agell A. Relación entre las maloclusiones y La respiración bucal em pacientes que asistieron al servicio de Otorrinolaringologia del Hospital Pediátrico San Juan de Dios. Acta Odontológica Venezolana. 2007; 45(3):1-5.

25. Albuquerque SSL, Duarte RC, Cavalcanti AL, Beltrão EM. Prevalência de más oclusões em crianças com 12 a 36 meses de idade em João Pessoa, Paraíba. R Dental Press Ortodon Ortop Facial. 2009; 14(6):50-7.

26. Casarin MT, Gindri G, Keske-Soares M, Mota HB. Alterações do sistema estomatognático em distúrbios de fala. Rev Soc Bras Fonoaudiol. 2006; 11(4):223-30.

27. Pastana SG, Costa SM, Chiappetta ALML. Análise da mastigação em indivíduos que apresentam mordida cruzada unilateral na faixa etária de 07 a 12 anos. Rev. CEFAC. 2007; 9(3):339-50.

28. Braga FL, Letti HCB, Berthold TB, Marchioro EM. Avaliação da profundidade palatina nos pacientes portadores de mordida cruzada posterior. Rev Odonto Ciência. 2006; 21(51):43-7.

29. Hoffelder LB, Braga CP, Lima EMS. Avaliação longitudinal da sobressaliência e da sobremordida em indivíduos portadores de maloclusäo de classe II dentária. Ortodon gauch. 2002;6(1):46-56,.

30. Monteiro VR, Brescovici SM, Delgado SE. A ocorrência de ceceio em crianças de oito a onze anos em escolas municipais. Rev Soc Bras Fonoaudiol. 2009;14(2):213-8.

DOI: 10.1590/S1516-18462010005000127

RECEBIDO EM: 21/01/2010

ACEITO EM: 30/07/2010

Endereço para correspondência:

Roberta Lopes de Castro Martinelli

Av. Ângelo Piva, 331

Brotas - SP

CEP: $17380-000$

E-mail: robertalcm@gmail.com 